06,11

\title{
Электрокалорический эффект в релаксоре магнониобате-скандонибате свинца
}

\author{
() Е.П. Смирнова, Г.Ю. Сотникова, Н.В. Зайцева, А.А. Капралов, Г.А. Гаврилов, А.В. Сотников \\ Физико-технический институт им. А.Ф. Иоффре РАН, \\ Санкт-Петербург, Россия \\ E-mail: esmirnoffa@gmail.com
}

(Поступила в Редакцию 17 апреля 2018 г.)

Проведены исследования электрокалорического эффекта, а также диэлектрических, пироэлектрических, акустических и пьезоэлектрических свойств в твердом растворе магнониобата-скандониобата свинца в смещающем электрическом поле. Обсуждаются диэлектрический и электромеханический вклады в пироэлектрический и электрокалорические эффекты.

Работа поддержана Российским фондом фундаментальных исследований, грант 18-02-00394.

DOI: 10.21883/FTT.2018.10.46524.111

\section{1. Введение}

Релаксоры характеризуются сильной дисперсией диэлектрической проницаемости в частотном диапазоне от миллигерц до гигагерц, при которой температура максимума проницаемости зависит от частоты измерения. По современным представлениям такое поведение определяется существованием полярных нанообластей (PNR) в параэлектрической матрице [1,2]. Отсутствие сформированной доменной структуры в области релаксорного состояния делает такие среды особенно восприимчивыми к внешним воздействиям, таким как температура, электрическое поле, деформация. Эффекты, возникающие при воздействии электрического поля, такие как индуцированный сегнетоэлектрический переход, диэлектрическая нелинейность, гигантская электрострикция, достаточно хорошо изучены $[3,4$ и ссылки там же]. В тоже время пироэлектрический и электрокалорический эффект (ЕСЕ) исследованы фрагментарно. Электрокалорический эффект определяется как обратимое изменение температуры диэлектрика при воздействии внешнего электрического поля в адиабатическом режиме. Изменение температуры в результате ЕСЕ выражается классическим соотношением [5]

$$
\delta T=-(T / \rho) \int\left(1 / c_{E}(T)\right)(\partial P(E) / \partial T)_{E} d E,
$$

где $T$ - температура, $E-$ напряженность электрического поля, $P(E, T)-$ поляризация, $c_{E}(T)-$ удельная теплоемкость при постоянной напряженности, $\rho$ плотность.

По своей природе ЕСЕ неразрывно связан с рядом сопутствующих эффектов, таких как пироэлектрический, пьезоэлектрический, а также с тепловым расширением, упругими свойствами и теплоемкостью [6].

Релаксоры являются одним из основных объектов при исследовании ЕСЕ. Они сохраняют симметрию неполярной параэлектрической фазы и не обладают пироэлектрическим, а также пьезоэлектрическим эффектом в области релаксорного состояния. Приложение внешнего электрического поля приводит к появлению полярного направления с преимущественной ориентацией по полю полярных нанообластей (PNR), которые, согласно современным представлениям о сегнетоэлектриках-релаксорах, существуют и могут также индуцироваться полем в области релаксорного состояния. Подавляющее число релаксоров обладает структурой перовскита с общей формулой $\mathrm{Pb}\left(B^{\prime} B^{\prime \prime}\right) \mathrm{O}_{3} \mathrm{c}$ различными неизовалентными катонами в $B$-положении.

ECE и, в некоторых случаях, суммарный пироэлектрический эффект, активно исследовался в релаксорах твердых растворах PMN-PT при низких концентрациях РТ $(x<0.25)$. Полученная для керамических образцов величина $\delta T$ варьировалась у разных авторов от 0.4 до $1.71^{\circ} \mathrm{C}[7-10]$. Даже у наиболее изученного состава $\mathrm{PMN}-0.1 \mathrm{PT}$ величина $\delta T$ равнялась и $1.25^{\circ} \mathrm{C}$ [7], и $0.45^{\circ} \mathrm{C}[8]$ при измерении одним и тем же методом с использованием термопары. Исследование монокристалла $\mathrm{PMN}-0.1 \mathrm{PT}$ (ориентация 111) показало близкую к керамике величину $\delta T=1^{\circ} \mathrm{C}[11]$.

Электрокалорический эффект исследовался в керамических твердых растворах скандотанталата-скандониобата свинца, максимальная величина $\delta T=1.25^{\circ} \mathrm{C}[12]$, а для чистого скандониобата свинца $-2^{\circ} \mathrm{C}[13]$.

ЕСЕ исследовался также в керамических образцарелаксорах классической системы твердых растворов $(1-x) \mathrm{BaTiO}_{3-x} \mathrm{BaZrO}_{3}(x=0.12$ и 0.2$)$ и максимальная величина $\delta T$ для состава $x=0.12$ равнялась, примерно, $1.6^{\circ} \mathrm{C}$ при поле $2 \mathrm{MV} / \mathrm{m}[14]$, а для состава с $x=0.2$, примерно, $4.5^{\circ} \mathrm{C}$ при поле $14.5 \mathrm{MV} / \mathrm{m}[15]$.

Обращает на себя внимание не только разброс полученных величин $\delta T$, но и отсутствие данных об индуцированном электрическим полем пироэлектрическом эффекте, а также таких сопутствующих и определяющих вторичный пироэффект свойствах [6], как индуцированный пьезоэффект и упругие свойства. 
Все вышесказанное стимулирует комплексное исследование ЕСЕ в сочетании с изучением индуцированного полем пироэлектрического и пьезоэлектрического эффектов, а также упругих свойств. В качестве объекта исследования был выбран твердый раствор магнонибата-скандониобата свинца, релаксорные свойства которого подтверждены изучением диэлектрических, электрострикционных, пироэлектрических свойств, а также акустических аномалий при температурах Бернса и $T^{*}[16,17]$.

\section{2. Эксперимент}

Керамические образцы твердого раствора $0.55 \mathrm{PbMg}_{1 / 3} \mathrm{Nb}_{2 / 3} \mathrm{O}_{3}-0.45 \mathrm{PbSc}_{1 / 2} \mathrm{Nb}_{1 / 2} \mathrm{O}_{3}-0.05 \mathrm{MgO}$ (PMN-PSN-M) были изготовлены с помощью реакции в твердой фазе. При синтезе, кроме оксида свинца $\mathrm{PbO}$, использовались промежуточные соединения (прекурсоры) колумбит $\left(\mathrm{MgNb}_{2} \mathrm{O}_{6}\right)$ и вольфрамит $\left(\mathrm{ScNbO}_{4}\right)$ [16]. Полнота образования твердых растворов контролировалась методом рентгеноструктурного анализа с использованием $\mathrm{Cu} K_{\alpha^{-}}$и $\mathrm{Co} K_{\alpha}$-излучения (рис. 1$)$. Полученная керамика была однофазной, обладала структурой перовскита. Добавление избытка оксида магния привело к увеличению плотности керамики до 97\% от теоретической.

Диэлектрические измерения были выполнены в диапазоне частот от $10 \mathrm{~Hz}$ до $1 \mathrm{MHz}$ с помощью измерителя импеданса PSM1735 NumetricQ при амплитуде измерительного поля $1 \mathrm{~V} / \mathrm{cm}$. Измерения проводились в режиме медленного нагревания с помощью термоэлектрических

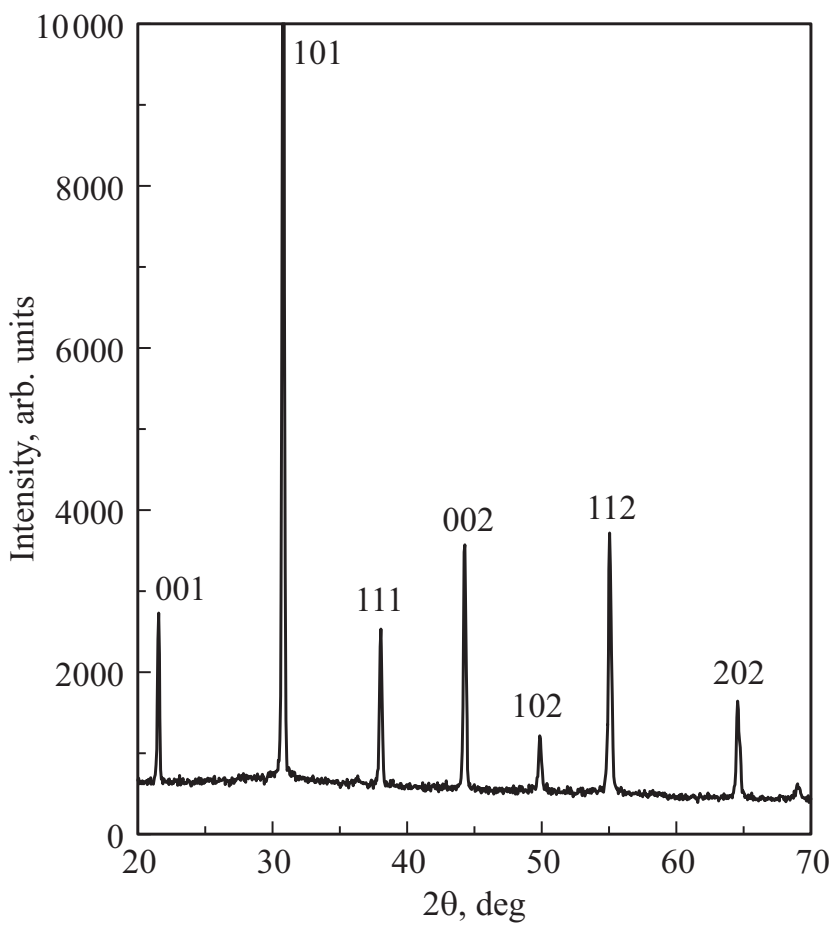

Pис. 1. Рентгенограмма твердого раствора $\mathrm{PMN}-\mathrm{PSN}-\mathrm{M}$ в интервале углов от 10 до $70^{\circ}$ по $2 \theta$. элементов Пельтье со скоростью $1 \mathrm{~K} / \mathrm{min}$ в диапазоне температур от 0 до $100^{\circ} \mathrm{C}$. Зависимость диэлектрической проницаемости от внешнего постоянного электрического поля исследовалась на частоте $1 \mathrm{KHz}$ с использованием стандартной схемы с разделительным конденсатором, высоковольтным источником и измерительным мостом Р5079. Образцы для диэлектрических измерений представляли собой диски диаметром $8 \mathrm{~mm}$ и толщиной $0.5 \mathrm{~mm}$ с электродами из возженного серебра.

Измерения продольной электрострикционной деформации проводились на гальваномагнитном дилатометpe в квазистатическом режиме при температурах $15-100^{\circ} \mathrm{C}$. Точность измерения относительной деформации составляла $10^{-6}$. Измеряемые образцы также имели форму дисков диаметром $8 \mathrm{~mm}$ и толщиной $3 \mathrm{~mm} \mathrm{c}$ возженными серебряными электродами.

Упругие коэффициенты $C$ керамических образцов определялись из продольной скорости звука, измеренной ультразвуковым эхо-импульсным методом с помощью установки „Фонон“ на частоте $10 \mathrm{MHz}$ в температурном диапазоне $15-100^{\circ} \mathrm{C}$. Образцы представляли собой керамические бруски размером $5 \times 5 \times 6 \mathrm{~mm}^{3}$.

Индуцированный постоянным электрическим полем пироэлектрический отклик в синтезированных образцах изучался с помощью динамического метода - метода модуляции интенсивности лазерного излучения (Laser Intensity Modulation Method - LIMM) [18]. Пироотклик исследовался в диапазоне температур от 10 до $80^{\circ} \mathrm{C}$ во внешних полях до $2 \cdot 10^{6} \mathrm{~V} / \mathrm{m}$. Модулированное тепловое воздействие на образец осуществлялось лазерным диодом $(\lambda=0.83 \mu \mathrm{m}$, мощность излучения до $100 \mathrm{~mW})$ путем управления его мощность излучения по гармоническому закону с частотой $0.1 \mathrm{~Hz}$.

Изменение и стабилизация температуры образца осуществлялось с помощью элементов Пельтье. Точность поддержания температуры составляла $0.1^{\circ}$. Измерение пиротока, так же, как и электрострикционной деформации, проводилось при нагревании образца; после каждого цикла измерений в электрическом поле образец прогревался до температуры $100^{\circ} \mathrm{C}$, чтобы исключить влияние предыстории образца на измеряемые свойства.

Исследование электрокалорического эффекта (ЕСЕ) проводились прямым методом с использованием квазиадиабатического калориметра, аналогичного описанному в $[19,20]$. Измерения $\delta T$ проводились платиновым термометром Pt100 с разрешением до $5 \cdot 10^{-3}$. Образцы для измерения представляли собой керамические диски диаметром $9 \mathrm{~mm}$ и толщиной $1 \mathrm{~mm}$ с электродами из возженного серебра. Все измерения проводились на механически свободных образцах.

\section{3. Экспериментальные результаты и их обсуждение}

Характерные для релаксоров температурные и полевые зависимости диэлектрической проницаемости $\varepsilon$, опубликованные в работе [16] для твердого раствора 


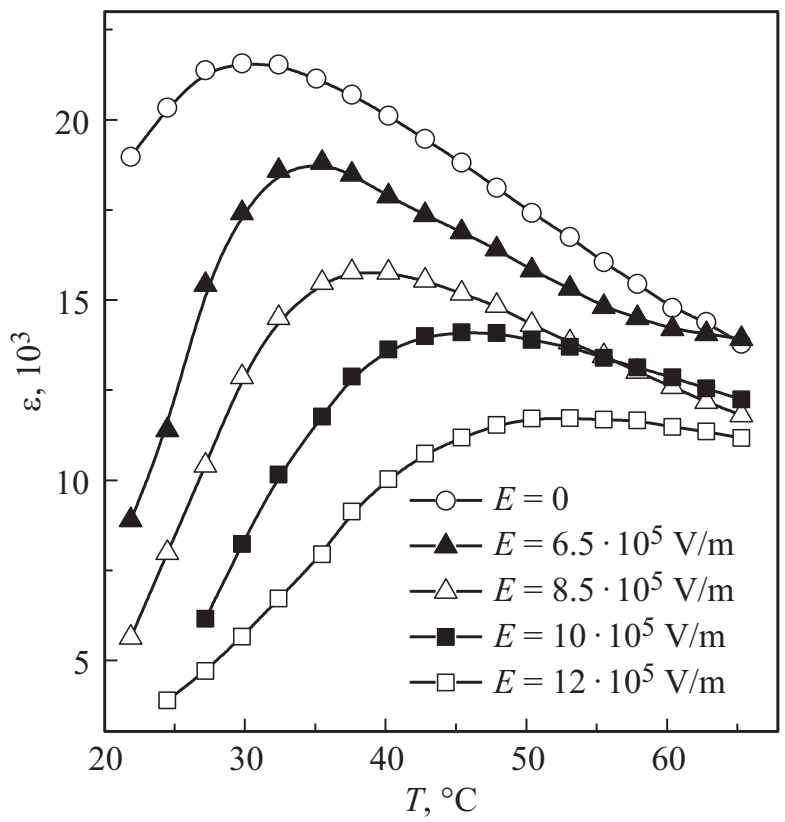

Рис. 2. Температурные зависимости диэлектрической проницаемости $\varepsilon(f=1 \mathrm{KHz})$ для керамики $\mathrm{PMN}-\mathrm{PSN}-\mathrm{M}$ при напряженностях электрического поля от 0 до $12 \cdot 10^{5} \mathrm{~V} / \mathrm{m}$.

PMN-PSN качественно подтвердились и для состава PMN-PSN-M с небольшим увеличением величины $\varepsilon$ в максимуме. Так, при приложении постоянного смещающего электрического поля вплоть до $12 \cdot 10^{5} \mathrm{~V} / \mathrm{m}$ зависимость $\varepsilon(T)$ размывается с понижением максимальной величины диэлектрической проницаемости и увеличением температуры максимума диэлектрической проницаемости $T_{m}=28^{\circ} \mathrm{C}(1 \mathrm{KHz})$ на $\sim 20^{\circ} \mathrm{C}$ (рис. 2$)$.

Температурные и полевые зависимости изменения температуры $\delta T$, возникающие в результате ЕСЕ, приведены на рис. 3, 4. Размытые максимумы $\delta T(T)$ наблюдаются при температуре около $30^{\circ} \mathrm{C}$ при всех приложенных напряженностях электрического поля $E$ в диапазоне от 6 до $15 \cdot 10^{5} \mathrm{~V} / \mathrm{m}$. Полевые зависимости $\delta T(E)$ при различных температурах в области температур максимумов диэлектрической проницаемости демонстрируют тенденцию к насыщению с максимальной величиной $\delta T=0.66^{\circ} \mathrm{C}$ при температуре $30^{\circ} \mathrm{C}$ и напряженности $15 \cdot 10^{5} \mathrm{~V} / \mathrm{m}$.

Кроме изменения температуры при действии электрического поля, ЕСЕ можно охарактеризовать электрокалорическим коэффициентом

$$
e=(\partial(\delta T) / \partial E)_{S},
$$

который определяется скоростью изменения $\delta T$. Полевые зависимости е при температурах, соответствующих температурам максимумов диэлектрической проницаемостей, демонстрируют пики при $30-33^{\circ} \mathrm{C}$ и напряженности поля $E=8-10 \cdot 10^{5} \mathrm{~V} / \mathrm{m}$ (рис. 5 ).

Известно, что электрокалорический коэффициент связан с пироэлектрическим коэффициентом, учитывая определение пирокоэффициента $p=(\partial P / \partial T)_{E}$, соотношением

$$
e / p=\left|T_{c_{E}}\right| .
$$

Максимальные значения $p(E)$ у измеренного твердого раствора составляют $37.5 \cdot 10^{-4} \mathrm{~cm}^{-2} \cdot \mathrm{K}^{-1}$ при $23-30^{\circ} \mathrm{C}$ и полях $10-13 \cdot 10^{5} \mathrm{~V} / \mathrm{m}$ (рис. 6).

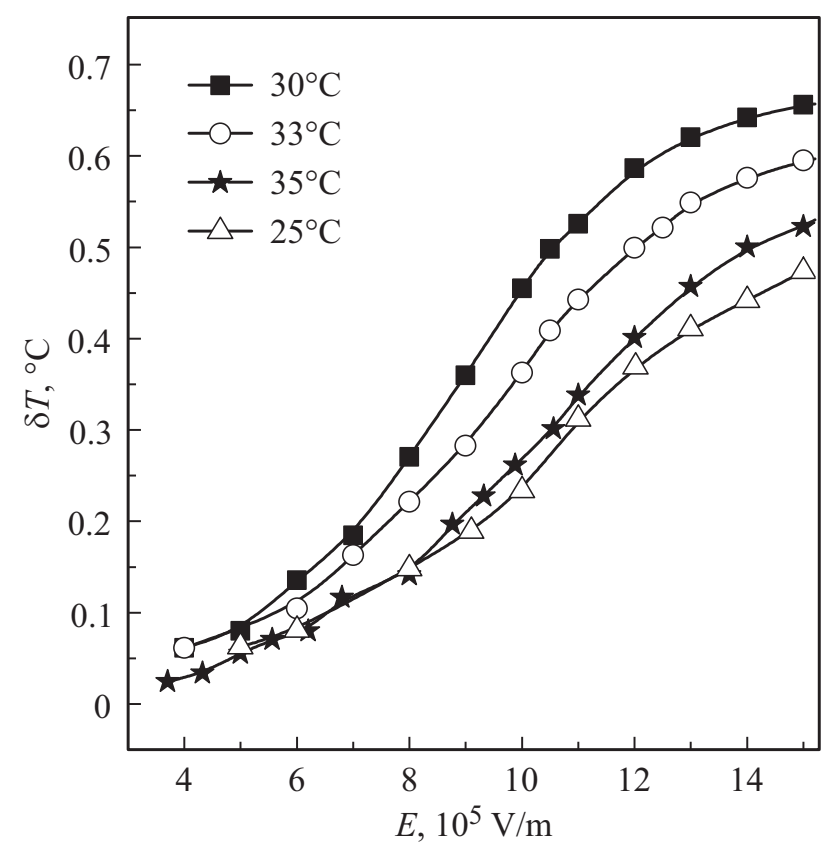

Рис. 3. Зависимость изменения температуры в результате электрокалорического эффекта $\delta T$ от электрического поля при температурах близких к $T_{m}$.

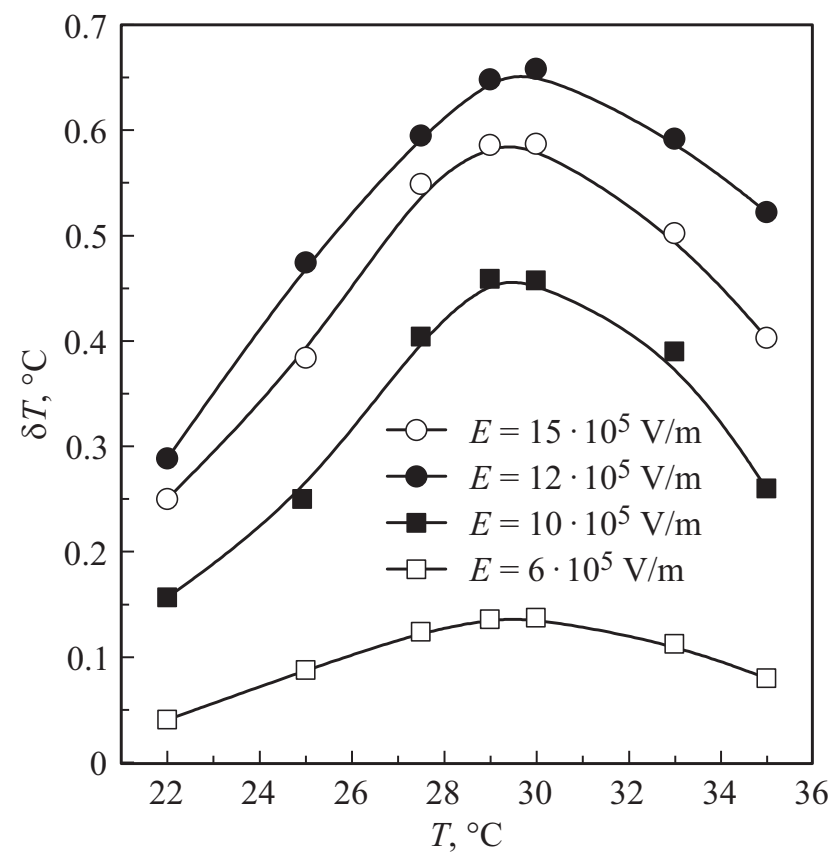

Рис. 4. Температурные зависимости изменения температуры $\delta T$ при напряженностях электрического поля от 6 до $15 \cdot 10^{5} \mathrm{~V} / \mathrm{m}$ при температурах близких к $T_{m}$. 


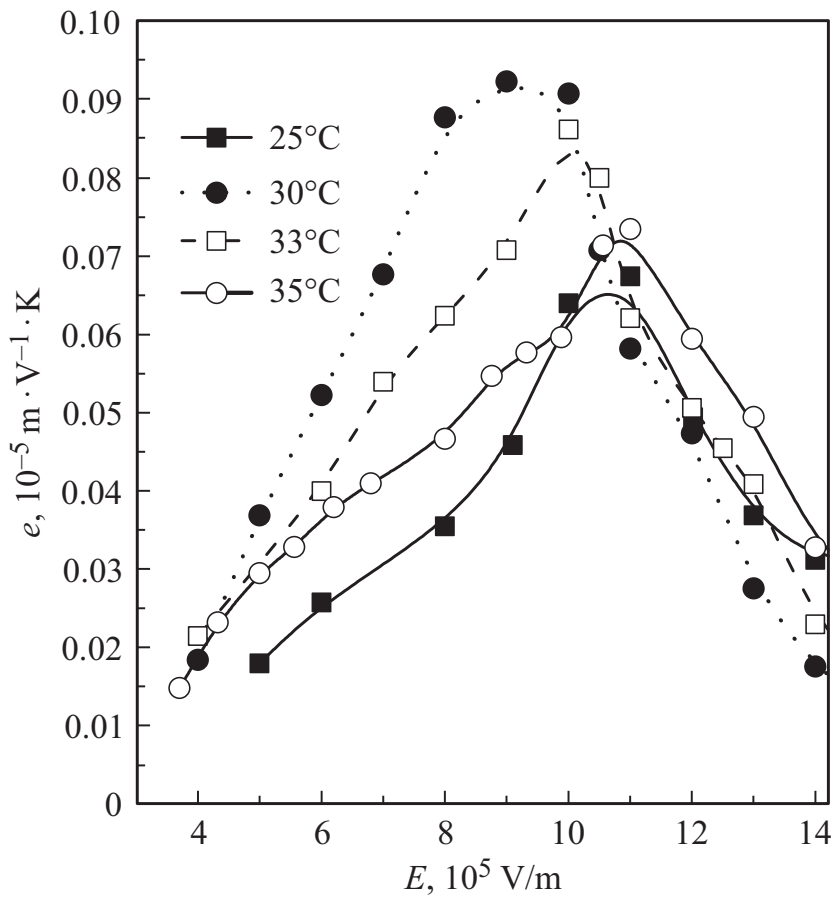

Рис. 5. Электрокалорический коэффициент $e$ как функция электрического поля при температурах близких к $T_{m}$.

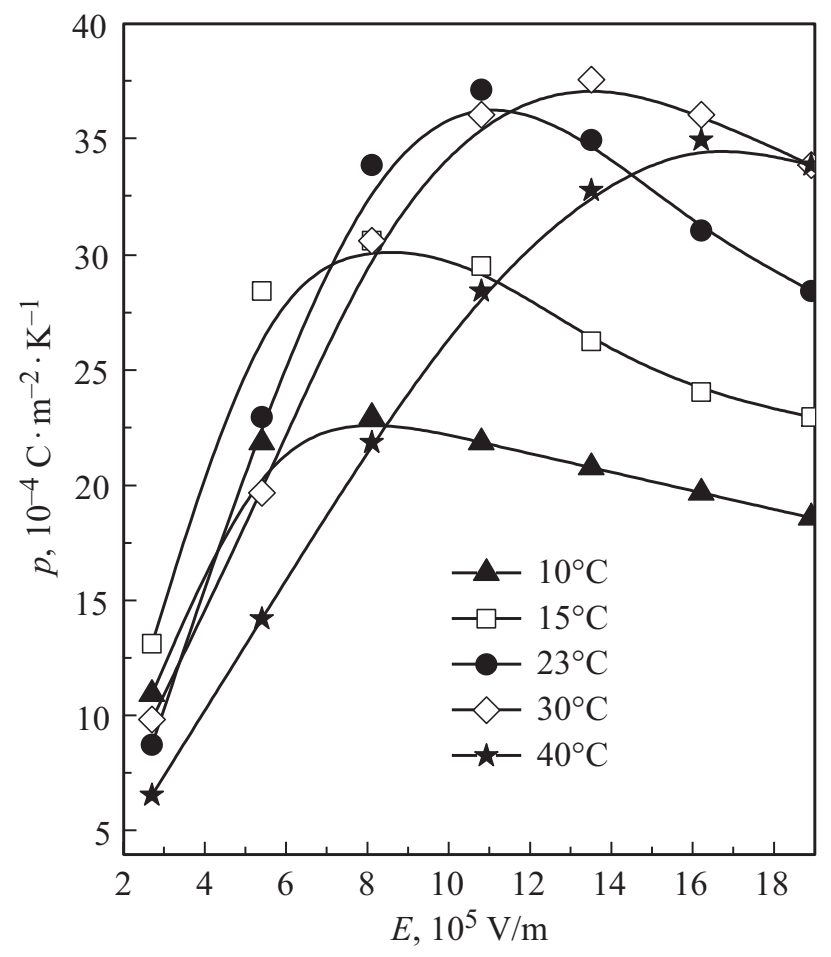

Рис. 6. Зависимость пироэлектрического коэффициента $p$ от напряженности электрического поля.

Полученные экспериментальные результаты позволяют не только выявить и сравнить электрокалорические и пироэлектрические свойства типичного релаксора, но и оценить вклад вторичного пироэффекта в измеряемый пироток. Как и в случае обычного пироэффекта, рассматриваются два вклада в индуцированный электрическим полем пироэффект. Это, прежде всего, диэлектрический вклад, он в нашем случае определяется температурной зависимостью индуцированной поляризации, к которой с понижением температуры может добавляться остаточная или спонтанная поляризация. Кроме того, линеаризованная стрикция (индуцированный пьезоэффект) определяет вторичный пироэффект, то есть вклад связанный с электромеханическим взаимодействием. Электромеханический вклад в термодинамический потенциал и соответствующий вклад во вторичный пироэффект обсуждались в работах $[16,21]$. Было получено выражение для компоненты пироэлектрического коэффициента, обусловленной электромеханическим взаимодействием $p^{\mathrm{II}} \approx d^{\mathrm{eff}} C \alpha$, где $d^{\mathrm{eff}}-$ эффективный пьезомодуль, зависящий от поля при данной температуре, $C-$ модуль упругости, зависящий от температуры и слабо (в пределах 2\%), зависящий от напряженности электрического поля [21], $\alpha-$ коэффициент теплового расширения, который варьируется в релаксорах на основе магнониобата свинца при температурах $T_{m}$ в пределах $2-4 \cdot 10^{-6}[22,23]$.

Полученные нами экспериментальные данные по зависимости индуцированной деформации от температуры и электрического поля, а также скорости звука $V$ позволили определить $d^{\mathrm{eff}}$ и $C$ (рис. 7). Обращает на себя внимание тот факт, что зависимости $d^{\mathrm{eff}}(T)$ и $C(T)$ имеют аномалии, практически, при одной и той же температуре. В свою очередь, это дало возможность определить температурную зависимость вторичного пирокоэффициента $p^{\mathrm{II}}$, в качестве примера, при $10 \cdot 10^{5} \mathrm{~V} / \mathrm{m}$, и сравнить зависимости $p^{\mathrm{II}}(T)$ и $p(T)$

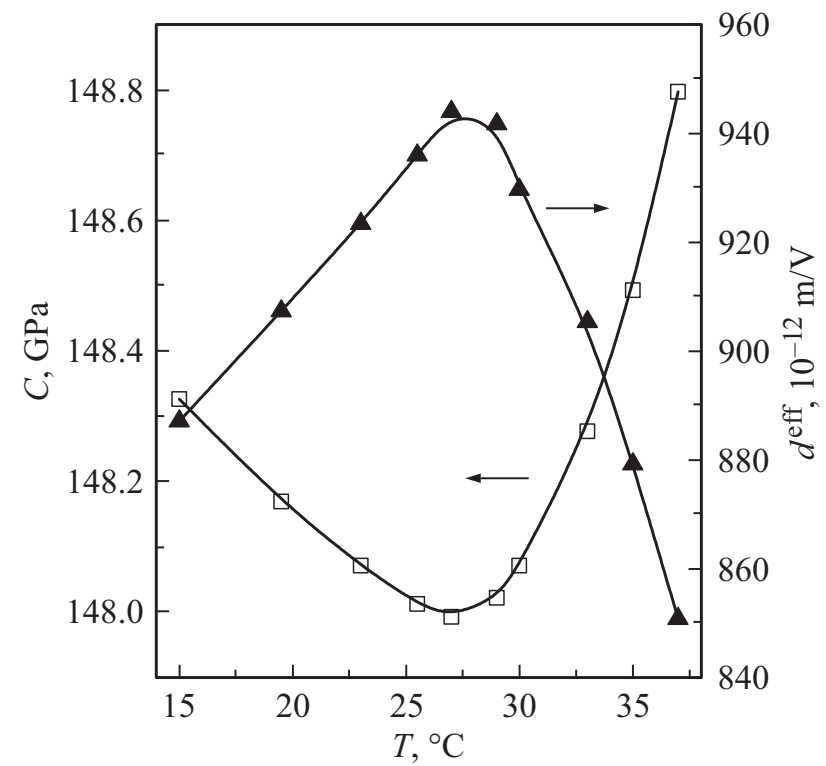

Рис. 7. Зависимости модуля упругости $C$ и эффективного пьезоэлектрического модуля $d^{\mathrm{eff}}$, измеренных при оптимальной напряженности электрического поля $E=10 \cdot 10^{5} \mathrm{~V} / \mathrm{m}$, от температуры. 

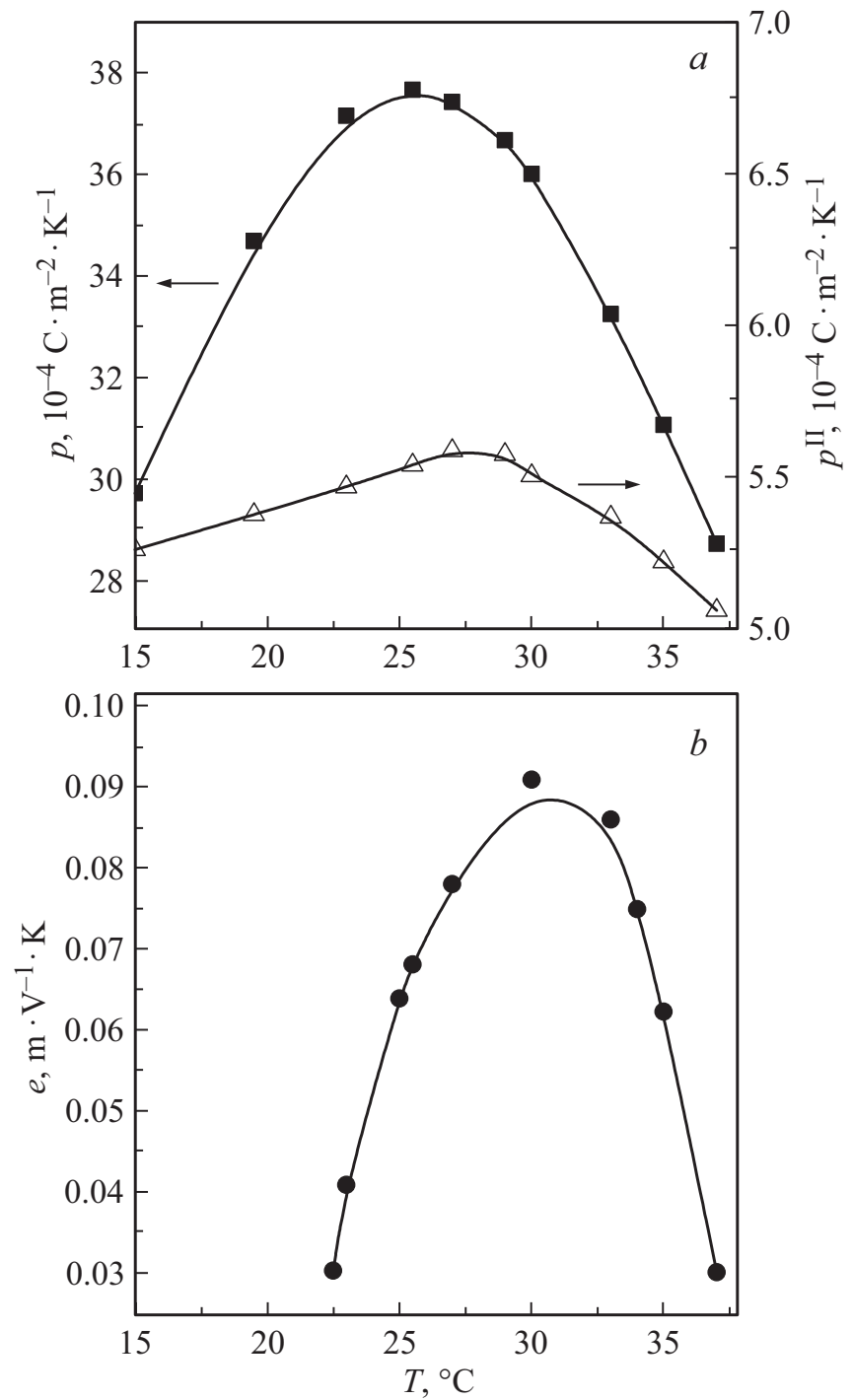

Рис. 8. Зависимости пироэлектрического эффекта $p$ и вторичного пироэлектрического коэффициента $p^{\text {II }}(a)$, а также электрокалорического коэффициента $e(b)$ от температуры $\left(E=10 \cdot 10^{5} \mathrm{~V} / \mathrm{m}\right)$.

(рис. $8, a)$. Видно, что аномалия $p^{\mathrm{II}}(T)$ сдвинута в сторону высоких температур по сравнению с кривой $p(T)$. Кроме того, влияние электромеханического вклада, составляющего около $15 \%$ от величины $p$, сводится не только к увеличению, но и к некоторому расширению температурной аномалии $p$. Исходя из соотношения для связи электрокалорического и пироэлектрического коэффициентов и того обстоятельства, что теплоемкость не связана с электромеханическим вкладом, можно сделать вывод, что электромеханический вклад (вторичный пироэффект) в электрокалорический эффект также составляет около 15\%. Следует заметить, что для керамики состава $0.68 \mathrm{BaTiO} 3-0.32 \mathrm{SrTiO}_{3}$, обладающей переходом первого рода, величина $p^{\mathrm{II}}$ составляет около $19 \%$ [24]. Обращает на себя внимание сравнительно резкая температурная зависимость как $\delta T$ (рис. 3), так и е (рис. 8, $b$ ). Происходит падение величин этих параметров до 2 раз при отклонении температуры на $\pm 6^{\circ} \mathrm{C}$ относительно температуры максимальных значений. Такое поведение сокращает рабочий диапазон температур в случае возможного применения этого материала и стимулирует дальнейшее исследование ЕСЕ в релаксорах.

\section{Список литературы}

[1] Г.А. Смоленский, В.А. Боков, В.А. Исупов, Н.Н. Крайник, Р.Е. Пасынков, А.И. Соколов. Физика сегнетоэлектрических явлений. Наука, Л. (1985).

[2] A.A. Bokov, Z.-G. Ye. J. Mater. Sci. 41, 31 (2006).

[3] М. Лайнс, А. Гласс. Сегнетоэлектрики и родственные им материалы. Мир, М. (1981).

[4] К.С. Александров, Б.П. Сорокин, С.И. Бурков. Эффективные пьезоэлектрические кристаллы для акустоэлектроники, пьезотехники и сенсоров. Изд-во СО РАН, Новосибирск (2008). Т. 2.

[5] W.N. Lawless. Phys. Rev. B 16, 433 (1977).

[6] Дж. Най. Физические свойства кристаллов. Мир, М. (1967).

[7] D.Q. Xiao, Y.C. Wang, R.L. Zhang, S.Q. Peng, J.G. Zhu, B. Yang. Mater. Chem. Phys. 57, 182 (1998).

[8] J. Hagberg, A. Uusimäki, H. Jantunen. Appl. Phys. Lett. 92, 132909 (2008).

[9] L. Shebanovs, K. Borman, W.N. Lawless, A. Kalvane. Ferroelectrics 273, 137 (2002).

[10] L. Shaobo, L. Yanqiu. Mater. Sci. Eng. B 113, 46 (2004).

[11] L. Luo, H. Chen, Y. Zhu, W. Li, H. Luo, Y. Zhang. J. Alloys Compd. 509, 8149 (2011).

[12] L.A. Shebanovs, E.H. Birks, K.J. Borma. Ferroelectrics 90, 165 (1989).

[13] E.H. Birks. Phys. Status Solidi A 94, 523 (1986).

[14] Yang-Bin Ma, C. Molin, V.V. Shvartsman, S. Gebhardt, D.C. Lupascu, K. Albe, Bai-Xiang Xu. J. Appl. Phys. 121, 024103 (2017).

[15] Xiao-Shi Qian, Hui-Jian Ye, Ying-Tang Zhang, Haiming Gu, Xinyu Li, C.A. Randall, Q.M. Zhang. Adv. Funct. Mater. 24, 1300 (2014).

[16] Е.П. Смирнова, С.Е. Александров, К.А. Сотников, А.А. Капралов, А.В. Сотников. ФТТ 45, 1245 (2003).

[17] E. Smirnova, S. Smirnov, A. Sotnikov, H. Schmidt, M. Weihnacht. Ferroelectrics 469, 67 (2014).

[18] S.B. Lang, D.K. Das-Gupta. Ferroelectrics 39, 1249 (1981).

[19] L. Shebanovs, K. Borman, W.N. Lawless, A. Kalvane, Ferroelectrics 273, 137 (2002).

[20] M. Sanlialp, V.V. Shvartsman, R. Faye, M.O. Karabasov, C. Molin, S. Gebhardt, E. Defay, D.C. Lupascu. Rev. Sci. Instr. 89, 034903 (2018).

[21] Е.П. Смирнова, А.В. Сотников. ФТТ 48, 95 (2006).

[22] L.E. Cross. Ferroelectrics 76, 241 (1987).

[23] P. Bonneau, P. Garnier, G. Calvarin, E. Husson, J.R. Cavarri, A.W. Hewat, A. Morell. J. Solid State Chem. 91, 350 (1991).

[24] Е.П. Смирнова, Г.Ю. Сотникова, Н.В. Зайцева, А.А. Капралов, Г.А. Гаврилов. Письма ЖТФ 44, 49 (2018).

Редактор К.В. Емцев 